\title{
The Association Between Hypovitaminosis D Status with Muscle Strength and Functional Capacity in a Brazilian Community-Dwelling Elderly Population: A Cross- Sectional Study
}

Aimee de Araujo Cabral Pelizari ( $\nabla$ aimeecabral0904@gmail.com )

Federal University of Minas Gerais

Danielle Aparecida Gomes Pereira

Federal University of Minas Gerais

Daniele Sirineu Pereira

Federal University of Minas Gerais

Adriana Netto Parentoni

Federal University of the Jequitinhonha and Mucuri Valleys

Leani Souza Máximo Pereira

Federal University of Minas Gerais

\section{Research Article}

Keywords: hypovitaminosis D, muscle strength, functional capacity, elderly

Posted Date: July 16th, 2021

DOI: https://doi.org/10.21203/rs.3.rs-684995/v1

License: (c) (i) This work is licensed under a Creative Commons Attribution 4.0 International License. Read Full License 


\section{Abstract}

Background: Although there have been studies on the association between hypovitaminosis $\mathrm{D}$ status with muscle strength and functional capacity, there were few studies on Brazilian community-dwelling elderly population. Therefore, this study aims to assess the association of hypovitaminosis $D$ with muscle strength and functional capacity in a sample Brazilian community-dwelling elderly population.

Methods: An analytical, cross-sectional observational study with a convenience sample was conducted. The 25(OH)D levels were assessed using an enzyme-linked fluorescent assay and classified according to the standardization of the Brazilian Society of Clinical Pathology/Laboratory Medicine. Hand grip strength (HGS) and isometric quadriceps strength (IQS) were measured using manual Jamar ${ }^{\circledR}$ and Lafayette ${ }^{\circledR} 01165$ dynamometers, respectively. Functional capacity was evaluated using the Short Physical Performance Battery (SPPB). Multiple linear regression models were used to assess the association of hypovitaminosis D with the HGS, IQS, and SPPB score via the Enter method. The models were adjusted for age, sex, presence of pain, level of physical activity, and use of vitamin D supplementation.

Results: A total of 150 elderly individuals (age: $67.18 \pm 5.33$ years) were included. According to the $25(\mathrm{OH}) \mathrm{D}$ levels, $60.7 \%$ had hypovitaminosis D (insufficient: $48 \%$, deficient: $12.7 \%$ ), and $39.3 \%$ had sufficient levels. No associations were found between hypovitaminosis D and the HGS $(p=0.84)$, LogIQS $(p=0.462)$, and SPPB score $(p=0.617)$. In the regression model, the influence of the vitamin $D$ levels on functional capacity was not significant, demonstrating no association between them.

Conclusion: Hypovitaminosis D was not associated with decreased muscle strength and functional capacity in the sample Brazilian community-dwelling elderly population. Longitudinal studies with measurement of the time of use and levels of vitamin D are encouraged.

\section{Background}

Hypovitaminosis $D$ is a frequent finding in older populations. Approximately 1 billion individuals have low vitamin D levels, regardless of ethnicity, age group, and geographic location [1, 2]. Depending on the population studied, the prevalence can reach up to $90 \%$, being considered by many researchers as a public health problem. Approximately $50-70 \%$ of European older individuals, $20-100 \%$ of Americans, and one third of Taiwanese and Japanese older individuals had vitamin D levels lower than $20 \mathrm{ng} / \mathrm{mL}$, indicating a deficiency $[3,4]$. In Brazil, despite being a country with a tropical climate, hypovitaminosis D occurs in several age groups mainly owing to a diet low in vitamin $D$, and affected individuals are rarely offered multivitamin supplementation [5]. In a recent systematic review with meta-analysis involving 340,476 Brazilians of different age groups, the mean level of vitamin $D$ was $27.06 \mathrm{ng} / \mathrm{mL}$, with the highest prevalence of deficiency among the older people group, which corresponded to $41.53 \%$ of the total population with vitamin D insufficiency [6].

This high prevalence in older people populations occurs owing to several factors, including decreased sun exposure, altered ability to synthesize this vitamin in the skin, impaired bowel absorption, poor dietary intake, and emergence of renal and gastrointestinal diseases [7]. Vitamin D receptors (VDRs) are present in more 
than 250 body sites, including muscle tissue. Inconclusive evidence shows that vitamin D is directly related to the metabolism of muscle energy and regulation of consumption and dynamics of mitochondrial oxygen, besides playing an important role in the regulation of muscle tone and contraction [8].

Taken together, changes in the vitamin D levels may contribute to the deterioration of various systems; however, the relationship of hypovitaminosis $\mathrm{D}$ with muscle strength and functional capacity in older people populations has been a subject of conflicting results [9-12]. Given the tropical climate of Brazil and the peculiarities inherent to the senescence of older people individuals living in a country with socio-economic and cultural inequities, we hypothesized that hypovitaminosis D would negatively influence the muscle strength and functional capacity of older people individuals. Thus, the aim of this study was to examine the association of hypovitaminosis D (insufficiency and deficiency) with muscle strength and functional capacity in a sample Brazilian community-dwelling older people population.

\section{Methods}

\section{Study design and participants}

This study was an analytical observational study with a cross-sectional design. A convenience sample of 150 Brazilian community-dwelling older people individuals of both sexes, aged 60 years or older, and recruited from August 2019 to February 2020 participated in the study. The exclusion criteria were as follows: cognitive decline detectable on the Mini-Mental State Examination [13], neurological sequelae, acute diseases, neoplasms, gastrectomy, use of prosthesis, use of drugs that interfere with the vitamin D levels, sequelae of diseases that could cause decreased muscle strength of the hands and lower limbs, severe sequelae of fracture, and previous orthopedic surgeries.

\section{Measurements}

\section{Sociodemographic and clinical variables}

To characterize the sample, we asked all participants to answer a clinical-sociodemographic questionnaire with items on age, sex, race, origin, marital status, schooling, profession, main diagnosis, presence of comorbidities, use of medications and supplements, and anthropometric data.

\section{Laboratory measurements}

The levels of 25(OH)D were measured using an enzyme-linked fluorescent assay. The tests were conducted in the laboratory of SARAH Network of Rehabilitation Hospitals. The reference levels were determined according to the standardization of the Brazilian Society of Clinical Pathology/Laboratory Medicine (SBPC/ML) for individuals aged 60 years or older: $30-100 \mathrm{ng} / \mathrm{mL}$, indicating vitamin $D$ sufficiency; 20-29.9 $\mathrm{ng} / \mathrm{mL}$, indicating insufficiency; and below $20 \mathrm{ng} / \mathrm{mL}$, indicating deficiency [5].

\section{Muscle strength}


Muscle strength was evaluated on the basis of hand grip strength (HGS) and isometric quadriceps strength (IQS). The Jamar ${ }^{\circledR}$ dynamometer was used to assess the HGS, as recommended by the American Society of Hand Therapist (ASHT) [14]. The Lafayette ${ }^{\circledR}$ model 01165 manual dynamometer was used to assess the IQS, following the recommendations standardized by Bohannon (2012) [15]. In both parameter evaluations, three repetitions were performed with the dominant limb, with a 1-minute rest interval between each measurement; subsequently, the arithmetic mean was calculated [16,17].

\section{Functional capacity}

Functional capacity was measured using the Short Physical Performance Battery (SPPB) adapted and validated for Brazilian older people individuals [18].

\section{Statistical analysis}

The Shapiro-Wilk test was used to evaluate the normality of the data. The quantitative descriptive data of the sample were summarized by measures of central tendency (medians and interquartile interval dispersions). The categorical variables of the study were described as absolute frequencies and percentages and the quantitative variables as medians (first quartile; third quartile) because the variables did not have a normal distribution as verified in the normality test.

As this study was an exploratory study conducted with a convenience sample, we initially tested the effect of the use of vitamin D and use of supplements on the study-dependent variables (HGS, IQS, and SPPB score) and vitamin D status to assess whether these variables influenced the outcome variables. The tests used were the Mann-Whitney (HGS and IQS), Pearson's exact chi-square (SPPB score), and asymptotic Pearson's chi-square tests (vitamin D status).

Multiple linear regression models were used to assess the association of the vitamin D levels with muscle strength (HGS and IQS) and functional capacity through the Enter method. The models were adjusted for age, sex, presence of pain, level of physical activity, and use of vitamin D supplementation. Since the IQS did not present a normal distribution, we decided to use the logarithm of the IQS (LogIQS).

The coefficient of multiple determination $\left(R^{2}\right)$ was used to quantify the strength of the association between muscle strength and the independent variables. The F-test was used to determine the statistical significance at $p$-values of $<0.05$. Regarding the assumptions of the model, the presence of multicollinearity was taken into account when the variance inflation factor was $>10$, and the tolerance was $<0.2$; homoscedasticity was verified by observing the graph of the predicted values and observed values and the normality of the nonstandardized residue. For all analyses, the SPSS version 23.0 software for Windows was used.

For all analyses, the significance level was set at 0.05, and the SPSS version 20.0 software (SPSS Inc., Chicago, IL, USA) was used.

\section{Results}


The prevalence of hypovitaminosis $D$ in the sample studied was $60.7 \%$. All 150 older people participants were classified as follows: $48 \%$ as having insufficient vitamin D levels ( $n=72$, median: 25.40 (range: 23.20$27.90 \mathrm{ng} / \mathrm{mL}$ ); $39.3 \%$, normal vitamin D levels ( $\mathrm{n}=59$, median: 33.60 (range: $31.77-38.10 \mathrm{ng} / \mathrm{mL}$ ); and $12.7 \%$, deficient vitamin $D$ levels $(n=19$, median: 18.30 (range: $14.70-19.00 \mathrm{ng} / \mathrm{mL}$ ). The descriptive analysis of the sociodemographic and clinical characteristics of the participants is presented in Table 1.

Interestingly, the participants who were using supplements $(p<0.0001)$ and vitamin $D(p<0.013)$ presented significantly lower HGS values in both analyses. Meanwhile, there was no significant difference in the IQS and SPPB score between the participants who used and who did not use supplements and vitamin $D(p \geq$ 0.05) (Table 2).

The multiple regression analysis showed that the vitamin D levels were not associated with the HGS and IQS. The influence of the vitamin D levels on the HGS and LogIQS lost its significance after the inclusion of the adjustment variables age, sex, presence of pain, level of physical activity, and use of supplements (Tables 3 and 4).

Regarding functional capacity, $2 \%$ had an SPPB score of $\leq 6,15.3 \%$ between 7 and 9 , and $82.7 \%$ between 10 and 12 (good). In the regression model, the influence of the vitamin $D$ level on functional capacity was not significant.

\section{Discussion}

This study conducted in a sample of 150 Brazilian community-dwelling older people individuals showed that the prevalence of hypovitaminosis D was high (60.7\%); in contrast, there was no association of hypovitaminosis $\mathrm{D}$ with muscle strength and functional capacity. This finding may be attributed to the fact that the sample included older people individuals with lower active age groups and few comorbidities, and the majority was practicing physical activity.

The high prevalence of hypovitaminosis $D$ in this sample corroborates previously reported findings. Recently, a systematic review and meta-analysis of 72 studies on the prevalence of hypovitaminosis $D$ in Brazil reported a rate of insufficiency of $45.85 \%$ and a rate of deficiency of $41.53 \%$. The study mentioned included all age groups; however, it highlighted a greater presence of hypovitaminosis D among the older people group [6].

In recent decades, research has confirmed the important role of vitamin $D$ in several outcomes, especially after the discovery of its activity on various organs and tissues [7]. Its relationship with the muscular system was more noticeable after the discovery of the VDRs in muscle tissue in the 1980s [19]. However, to date, the evidence on the influence of vitamin D deficiency on the muscle strength and functional capacity of older people individuals is still inconclusive. Aspell et al. (2019) evaluated 4,157 individuals with a mean age of $69.8 \pm 6.9$ years and reported that vitamin D deficiency was associated with decreased muscle strength among English community-dwelling older people individuals [20]. The value adopted to verify the vitamin deficiency used in this study was $30 \mathrm{nmol} / \mathrm{L}$, which corresponds to $12 \mathrm{ng} / \mathrm{mL}$. In our study, the recommendations of the SBPC/ML established levels below $30 \mathrm{ng} / \mathrm{mL}$ to indicate insufficiency and below 20 
$\mathrm{ng} / \mathrm{mL}$ to indicate deficiency. The absence of an international standardization for the classification of vitamin $\mathrm{D}$ deficiency hampers a comparative analysis between the two studies [21].

In 2018, Mendes et al. evaluated 1,425 older people individuals (mean age: $75.4 \pm 7.5$ years in women and $74.2 \pm 6.7$ years in men) and found a significant association between vitamin $D$ deficiency and decreased gait speed and HGS, especially in men (41.5\% of the total sample) [22]. Of the participants of our study, only $28 \%$ were men, with a much smaller age group $(67.18 \pm 5.33$ years), which could explain, at least in part, the conflicting results. It is already established that men have greater muscle strength than women in all age groups and that the higher the age group, the lower the muscle strength and functional capacity [23]. Verlaan et al. (2018) conducted a multicenter study of 380 community-dwelling older people individuals aged over 65 years from 6 European countries (Belgium, Germany, Ireland, Italy, Sweden, and the United Kingdom) [24]. They found that older people individuals with vitamin $D$ deficiency also presented decreased muscle mass (on DXA), strength (HGS), and functional performance in the SPPB (4-9 points). In our study, despite low schooling and living in a developing country, such as Brazil, $82.7 \%$ of the older people participants displayed good functional performance; further, $50.6 \%$ practiced regular physical activity, with few comorbidities, and were often exposed to sunlight. This differentiated profile of the Brazilian older people individuals may have contributed to the results found.

Notably, some studies have demonstrated similar results: not finding an association between hypovitaminosis D and decreased muscle strength and functional capacity. Mathei et al. (2013) assessed the relationship between the levels of 25(OH)D, HGS, and gait speed and balance test findings in 367 octogenarians. In this sample, only $12.8 \%$ presented vitamin D levels of $30 \mathrm{ng} / \mathrm{mL}$ or more [11]. Interestingly, there was no association found between hypovitaminosis $D$ and the variables studied, although it was expected that the older age group would present worse results, which did not occur. Verreault et al. (2002) followed a cohort of 628 women (age: $\leq 65$ years) for 3 years, performing evaluations every 6 months. The sample was divided into three groups according to the levels of vitamin $D(\leq 10 \mathrm{ng} / \mathrm{mL}, 10-20 \mathrm{ng} / \mathrm{mL}$, and $\geq 21 \mathrm{ng} / \mathrm{mL}$ ) at baseline. Their analysis showed that the decline in strength (HGS) and muscle function (SPPB score) was similar in the three groups, regardless of the initial level of vitamin D [25]. Annweiler et al. (2009) evaluated the HGS, IQS, renal function, and parathyroid hormone (PTH) and calcium levels in 440 older people women with a mean age of $80.1 \pm 3.5$ years [26]. No association was found between vitamin $D$ deficiency and decreased muscle strength. Advanced age and a higher number of chronic degenerative diseases were associated with greater decreases in muscle strength. The association of muscle weakness with increasing age is already well established in the literature and was one of the findings.

A possible physiological explanation for the lack of association of vitamin $D$ deficiency with muscle strength and functional capacity in the older people population found in this study could be the decrease in the number of VDRs in the muscle tissue. Currently, the exact mechanism of the relationship between receptors and vitamin $D$ deficiency is not yet established, that is, whether this reduction is caused by vitamin $D$ deficiency itself (negative regulation of the receptor) or if by another factor inherent to aging [27].

The complex interaction between muscle strength and vitamin D, especially in older people individuals, is still contradictory. The existence of possible confounding factors, such as the level of PTH, presence of kidney diseases, comorbidities, use of medications or supplements, and practice of physical activity, is not always 
controlled in studies, which may have contributed to the reporting of divergent results. Further, the large methodological variability, especially between the forms of measurement and classification of $25(\mathrm{OH}) \mathrm{D}$, and diversity of assessments for muscle strength and functional capacity limit the comparison of data and may explain, at least in part, the large disparity of the findings. Conversely, the heterogeneity of the aging process, senility, clinical and socio-cultural factors, and life habits could also interfere in muscle and functional performance and should also then be considered.

In this study, sex (female), increased age, presence of pain, and use of supplements were more related to decreased HGS than the serum level of 25(OH)D. Both sex and age are factors that explain the decrease in muscle strength, that is, men have higher HGS than women, and muscle strength decreases with age [23].

Our study had an exploratory design; however, it is important to highlight that we analyzed not only the serum levels of vitamin $D$ and the functionalities but also the use of vitamin supplements. Herein, we found that the older people participants who were using some type of supplementation had lower HGS, which may suggest that they were experiencing functional decline and thus had the need for supplementation.

There was no association between hypovitaminosis D and the IQS; increased age, sex, presence of pain, and physical activity were most related to this variable. The participants of this study were healthy communitydwelling older people individuals, of whom $50.6 \%$ practiced regular physical activity, and $82.7 \%$ had a good functional status. The performance of physical activity is considered a premise to reduce the physiological losses inherent to aging; it is widely studied and has been proven to be efficient in maintaining functional capacity and muscle strength [28]. The presence of pain could be a source of bias for the performance of muscle contraction required in the IQS assessment. In our sample, the older people participants who complained of pain in some joint presented lower quadriceps strength. In a systematic review with metaanalysis, Latey et al. (2017) reported that the intensity, frequency, and duration of pain are associated with muscle weakness [29].

Our study used the SPPB for the evaluation of functional capacity. Most of the older people participants presented good performance in the SPPB, which resulted in a low variability in this variable. Previous studies have reported that life habits, such as the practice of physical activity and good diet, can influence the functional performance of older people individuals; however, the influence of the vitamin $D$ levels on these outcomes needs further investigation in future studies $[24,26]$.

This study has several limitations. First, as a cross-sectional study, which has an inherent limitation of not allowing the establishment of a cause-effect relationship. Therefore, the findings must be analyzed with caution. Second, the medications and supplements taken by the participants were not qualitatively assessed. Last, we did not evaluate the diet or time of sun exposure, which are factors that may influence the level of vitamin $\mathrm{D}$.

\section{Conclusions}

In conclusion, among the healthy Brazilian community-dwelling older people participants with good functional performance, there was no association found between hypovitaminosis D and the HGS, IQS, and 
SPPB score. The better muscle and functional performance observed may be attributed to the fact that the sample had a lower age and was practicing physical activity and living in a tropical country. Future studies should be conducted to achieve a better understanding of the influence of vitamin $D$ level alterations on the muscle strength and functional capacity of older people individuals, especially in the Brazilian population wherein we perceive a scarcity of this information.

\section{Abbreviations}

25(OH)D: 25-hidroxivitamina D; HGS: hand grip strength; IQS: isometric quadriceps strength; SPPB: Short Physical Performance Battery; PTH: parathyroid hormone.

\section{Declarations}

\section{Acknowledgments}

We thank all The SARAH Network of Rehabilitation Hospitals for providing the physical space, laboratories, and instruments for this study; and statistician Luiz Sérgio Vaz for the collaboration. We express our sincere gratitude in memory of Professor Dr. Lygia Paccini Lustosa for the conception of the initial work.

\section{Authors' contributions:}

Pelizari, A.A.C: Conceptualization; Investigation; Writing; Pereira, D.A.G.: Formal analysis; Writing - Review \& Editing; Pereira, D.S.: Formal analysis; Writing - Review \& Editing; Parentoni, A.N.: Writing - Review \& Editing; Pereira, L.S.M.: Methodology; Writing - Review \& Editing; Supervision; Project administration. All authors read and approved the final manuscript.

\section{Availability of data and materials}

The datasets used and/or analyzed during the current study are available from the corresponding author on reasonable request.

\section{Funding}

This study did not receive funding from agencies in the public, commercial, or non-profit sectors.

\section{Ethics approval and consent to participate}

All the experimente protocol for involving humans was in accordance to guidelines of national, international, institutional, and Declaration of Helsinki in the manuscript. All participants provided written informed consent. The study was approved by the Ethics Committees of the SARAH Network of Rehabilitation Hospitals and the Federal University of Minas Gerais, under the CAAE numbers 06716919.5.0000.0022 and 06716919.5.3001.5149, respectively. Data were anonymized and de-identifiable with no personal information, with careful protection on confidentiality.

\section{Consent for publication}


Not applicable.

\section{References}

1. Holick MF. Vitamin D Deficiency. N Engl J Med [Internet]. 2007 Jul 19 [cited 2018 Oct 28];357(3):266-81. Available from: http://www.ncbi.nlm.nih.gov/pubmed/17634462

2. Palacios $C$, Gonzalez L. Is vitamin D deficiency a major global public health problem? J Steroid Biochem Mol Biol [Internet]. 2014;144(PART A):138-45. Available from:

http://dx.doi.org/10.1016/j.jsbmb.2013.11.003

3. Holick MF, Binkley NC, Bischoff-Ferrari HA, Gordon CM, Hanley DA, Heaney RP, et al. Evaluation, Treatment, and Prevention of Vitamin D Deficiency: an Endocrine Society Clinical Practice Guideline. J Clin Endocrinol Metab [Internet]. 2011 Jul [cited 2018 Nov 17];96(7):1911-30. Available from: http://www.ncbi.nlm.nih.gov/pubmed/21646368

4. Chan R, Chan D, Woo J, Ohlsson C, Mellström D, Kwok T, et al. Not all elderly people benefit from vitamin D supplementation with respect to physical function: Results from the osteoporotic fractures in men study, Hong Kong. J Am Geriatr Soc. 2012;60(2):290-5.

5. Ferreira CES, Maeda SS, Batista MC, Lazaretti-Castro M, Vasconcellos LS, Madeira M, et al. Consensus reference ranges of vitamin $D[25(\mathrm{OH}) \mathrm{D}]$ from the Brazilian medical societies. Brazilian Society of Clinical Pathology/Laboratory Medicine (SBPC/ML) and Brazilian Society of Endocrinology and Metabolism (SBEM). J Bras Patol e Med Lab. 2017;53(6):377-81.

6. Pereira-Santos M, Santos JYG dos, Carvalho GQ, Santos DB dos, Oliveira AM. Epidemiology of vitamin D insufficiency and deficiency in a population in a sunny country: Geospatial meta-analysis in Brazil. Crit Rev Food Sci Nutr. 2019;59(13):2102-9.

7. Pilz S, Trummer C, Pandis M, Schwetz V, Aberer F, Grübler M, et al. Vitamin D: Current Guidelines and Future Outlook. Anticancer Res [Internet]. 2018 Jan 20 [cited 2018 Oct 28];38(2):1145-51. Available from: http://www.ncbi.nlm.nih.gov/pubmed/29374751

8. Crescioli $C$. Targeting age-dependent functional and metabolic decline of human skeletal muscle: The geroprotective role of exercise, myokine IL-6, and vitamin D. Int J Mol Sci. 2020;21(3).

9. Gerdhem P, Ringsberg KAM, Obrant KJ, Akesson K. Association between 25-hydroxy vitamin D levels, physical activity, muscle strength and fractures in the prospective population-based OPRA Study of Elderly Women. Osteoporos Int. 2005;16(11):1425-31.

10. Houston DK, Cesari M, Ferrucci L, Cherubini A, Maggio D, Bartali B, et al. Association between vitamin D status and physical performance: The inCHIANTI study. Journals Gerontol - Ser A Biol Sci Med Sci. 2007;62(4):440-6.

11. Mathei C, Van Pottelbergh G, Vaes B, Adriaensen W, Gruson D, Degryse J-M. No relation between vitamin D status and physical performance in the oldest old: results from the Belfrail study. Age Ageing [Internet]. 2013 Mar 1 [cited 2018 Oct 28];42(2):186-90. Available from:

http://www.ncbi.nlm.nih.gov/pubmed/23360776

12. Vaes AMM, Brouwer-Brolsma EM, Toussaint $N$, de Regt $M$, Tieland M, van Loon LJC, et al. The association between 25-hydroxyvitamin $\mathrm{D}$ concentration, physical performance and frailty status in older 
adults. Eur J Nutr [Internet]. 2018 Apr 25 [cited 2018 Oct 28]; Available from:

http://www.ncbi.nlm.nih.gov/pubmed/29691654

13. Bertolucci PHF, Brucki SMD, Campacci SR, Juliano Y. O Mini-Exame do Estado Mental em uma população geral: impacto da escolaridade. Arq Neuropsiquiatr. 1994;52(1):01-7.

14. Fess EE. Clinical assessment recommendations. 2nd ed. Therapist AS of H, editor. Chicago: In: Casanova JS; 1992. 41-5 p.

15. Bohannon RW. Hand-Held Dynamometry: A Practicable Alternative for Obtaining Objective Measures of Muscle Strength. Phys Ther. 2012;71:301-15.

16. Bandinelli S, Benvenuti E, Del Lungo I, Baccini M, Benvenuti F, Di lorio A, et al. Measuring muscular strength of the lower limbs by hand-held dynamometer: a standard protocol. Aging (Milano) [Internet]. 1999 Oct [cited 2019 May 4];11(5):287-93. Available from:

http://www.ncbi.nlm.nih.gov/pubmed/10631877

17. Rantanen T, Guralnik JM, Foley D, Masaki K, Leveille S, Curb JD, et al. Midlife hand grip strength as a predictor of old age disability. JAMA [Internet]. 1999 Feb 10 [cited 2018 Nov 17];281(6):558-60. Available from: http://www.ncbi.nlm.nih.gov/pubmed/10022113

18. Nakano MM. Versao Brasileira da Short Physical Performance Battery - SPPB: Adaptaçâo Cultural e Estudo de Confiabilidade. Vol. 111. 2007.

19. Simpson RU, Thomas GA, Arnold AJ. Identification of 1,25-dihydroxyvitamin D3 receptors and activities in muscle. J Biol Chem. 1985;260(15):8882-91.

20. Niamh Aspell, Eamon Laird, Martin Healy, Brain Lawlor MO. Vitamin D Deficiency Is Associated With Impaired Muscle Strength And Physical Performance In Community-Dwelling Older Adults: Findings From The English Longitudinal Study Of Ageing. Clin Interv Aging. 2019;14:1751-61.

21. Pludowski P, Holick MF, Grant WB, Konstantynowicz J, Mascarenhas MR, Haq A, et al. Vitamin D supplementation guidelines. J Steroid Biochem Mol Biol [Internet]. 2018;175:125-35. Available from: http://dx.doi.org/10.1016/j.jsbmb.2017.01.021

22. Mendes, J.; Santos, A.; Borges, N.; Afonso, C.; Moreira, P.; Padrão, P.; Negrão, R. Amaral TF. Vitamin D status and functional parameters: A cross-sectional study in an older population. PLoS One. 2018;Aug $21 ; 13($.

23. Sialino LD, Schaap LA, Van Oostrom SH, Nooyens ACJ, Picavet HSJ, Twisk JWR, et al. Sex differences in physical performance by age, educational level, ethnic groups and birth cohort: The Longitudinal Aging Study Amsterdam. PLoS One [Internet]. 2019;14(12):1-12. Available from: http://dx.doi.org/10.1371/journal.pone.0226342

24. Verlaan S, Maier AB, Bauer JM, Bautmans I, Brandt K, Donini LM, et al. Sufficient levels of 25hydroxyvitamin $D$ and protein intake required to increase muscle mass in sarcopenic older adults - The PROVIDE study. Clin Nutr [Internet]. 2018;37(2):551-7. Available from: https://doi.org/10.1016/j.clnu.2017.01.005

25. Verreault R, Semba RD, Volpato S, Ferrucci L, Fried LP, Guralnik JM. Low Serum Vitamin D Does Not Predict New Disability or Loss of Muscle Strength in Older Women. J Am Geriatr Soc [Internet]. 2002 May 
1 [cited 2019 Feb 16];50(5):912-7. Available from: http://doi.wiley.com/10.1046/j.15325415.2002.50219.x

26. Annweiler C, Beauchet O, Berrut G, Fantino B, Bonnefoy M, Herrmann FR, et al. Is there an association between serum 25-hydroxyvitamin $D$ concentration and muscle strength among older women? Results from baseline assessment of the EPIDOS study. J Nutr Heal Aging. 2009;13(2):90-5.

27. Bischoff HA, Stahelin HB, Urscheler N, Ehrsam R, Vonthein R, Perrig-Chiello P, et al. Muscle strength in the elderly: Its relation to vitamin D metabolites. Arch Phys Med Rehabil. 1999;80(1):54-8.

28. Souza CF de, Vieira MCA, Nascimento RA do, Moreira MA, Câmara SMA da, Maciel ÁCC, et al. Relationship between strength and muscle mass in middle-aged and elderly women: a cross-sectional study. Rev Bras Geriatr e Gerontol [Internet]. 2017 Oct [cited 2019 May 4];20(5):660-9. Available from: http://www.scielo.br/scielo.php?script=sci_arttext\&pid=S1809-98232017000500660\&lng=en\&tlng=en

29. Latey PJ, Burns J, Hiller CE, Nightingale EJ. Relationship between foot pain, muscle strength and size : a systematic review. 2017;103:2016-8.

\section{Tables}

\section{Table 1}

Sociodemographic and clinical characteristics of the participants. 


\begin{tabular}{|c|c|c|}
\hline Characteristics & $n=(150)$ & $\mathrm{N}=(\%)$ \\
\hline \multicolumn{3}{|l|}{ Gender } \\
\hline Female & 108 & 72 \\
\hline Male & 42 & 28 \\
\hline \multicolumn{3}{|l|}{ Age (years) } \\
\hline $60-69$ years & 105 & 70 \\
\hline $70-79$ years & 41 & 27,3 \\
\hline $80>$ years & 4 & 2,7 \\
\hline \multicolumn{3}{|l|}{ Ethnicity } \\
\hline White & 77 & 51,3 \\
\hline Half-breed & 62 & 41,3 \\
\hline Asian & 2 & 1,3 \\
\hline Black & 9 & 6,0 \\
\hline \multicolumn{3}{|c|}{ Education (years) } \\
\hline unlettered & 7 & 4,7 \\
\hline$<5$ years & 63 & 42,0 \\
\hline 6 a 10 years & 23 & 15,3 \\
\hline 11 a 15 years & 33 & 22,00 \\
\hline 16 years $>$ & 24 & 16,0 \\
\hline \multicolumn{3}{|l|}{$\mathrm{SAH}^{+}$} \\
\hline No & 57 & 38,0 \\
\hline Yes & 93 & 62,0 \\
\hline \multicolumn{3}{|l|}{$\mathrm{DM}^{\ddagger}$} \\
\hline No & 104 & 69,3 \\
\hline Yes & 46 & 30,7 \\
\hline \multicolumn{3}{|c|}{ Other comorbidities } \\
\hline No & 120 & 80 \\
\hline Yes & 30 & 20 \\
\hline \multicolumn{3}{|l|}{ Use of drogs } \\
\hline No & 28 & 18,7 \\
\hline
\end{tabular}




\begin{tabular}{lll} 
Yes & 122 & 81,3 \\
\hline Use of supplements & & \\
\hline No & 90 & 90 \\
\hline Yes & 60 & 60 \\
\hline
\end{tabular}

Physical activity

\begin{tabular}{lll}
\hline No & 74 & 49,3 \\
\hline Yes & 76 & 50,7
\end{tabular}

${ }^{\dagger}$ Systemic Arterial Hypertension; ${ }^{\ddagger}$ Diabetes Mellitus

\section{Table 2}

Comparison of the variables HGS, IQS, SPPB and vitamin D status in relation to the use of supplements and use of vitamin D.

\begin{tabular}{|c|c|c|c|c|c|c|}
\hline \multirow{2}{*}{ P-value } & \multicolumn{3}{|c|}{ Use of supplements } & \multicolumn{3}{|c|}{ Use of vitamin D } \\
\hline & Yes $n=47$ & No $n=103$ & P-value & Yes $n=37$ & No $n=11$ & \\
\hline $\begin{array}{l}\text { HGS } \\
\text { Median (Q1;Q3) }\end{array}$ & $\begin{array}{l}23,3 \\
(18,7 ; 28,7)\end{array}$ & $\begin{array}{l}29,3 \\
(24,0 ; 36,7)\end{array}$ & $<0,0001^{1}$ & $\begin{array}{r}24,0 \\
(20,7 ; 29,7)\end{array}$ & $\begin{array}{l}29,0 \\
(23,5 ; 35,3)\end{array}$ & $0,013^{1}$ \\
\hline $\begin{array}{l}\text { QIS } \\
\text { Median (Q1;Q3) }\end{array}$ & $\begin{array}{l}200,1 \\
(167,7 ; 230,8)\end{array}$ & $\begin{array}{l}201,2 \\
(168,6 ; 256,4)\end{array}$ & $0,403^{1}$ & $\begin{array}{l}199,4 \\
(162,4 ; 251,0)\end{array}$ & $\begin{array}{l}201,2 \\
(168,9 ; 251,4)\end{array}$ & $0,624^{1}$ \\
\hline $\begin{array}{l}\text { SPPB } \\
\text { Median(Q1;Q3) }\end{array}$ & $\begin{array}{l}11,0 \\
(10,0 ; 12,0)\end{array}$ & $\begin{array}{r}11,0 \\
(9,0 ; 12,0)\end{array}$ & $0,384^{1}$ & $\begin{array}{l}11,0 \\
(10,0 ; 11,0)\end{array}$ & $\begin{array}{l}11,0 \\
(10,0 ; 12,0)\end{array}$ & $0,153^{1}$ \\
\hline SPPB & & & & & & \\
\hline 0 a 6 & $2(66,7)$ & $1(33,3)$ & & $2(66,7)$ & $1(33,3)$ & \\
\hline 7 a 9 & $10(43,5)$ & $13(56,5)$ & $0,142^{2}$ & $6(26,1)$ & $17(73,9)$ & $0,251^{2}$ \\
\hline 10 a 12 & $35(28,2)$ & $89(71,8)$ & & $29(23,4)$ & $95(76,6)$ & \\
\hline Vitamin D status & & & & & & \\
\hline Sufficiency & $17(28,8)$ & $42(71,2)$ & $0,592^{3}$ & $18(30,5)$ & $41(69,5)$ & $0,181^{3}$ \\
\hline $\begin{array}{l}\text { Hypovitaminosis } \\
\text { D }\end{array}$ & $30(33,0)$ & $61(67,0)$ & & $19(20,9)$ & $72(79,1)$ & \\
\hline
\end{tabular}


1 Mann Whitney Test; 2 Pearson's exact chi-square test; 3 Asymptotic Pearson's Chi-square test.

\section{Table 3}

Results of the selection of variables in the multivariate HGS model

$\begin{array}{lllllll}\text { Variable } & \text { p model 1 } & \text { p model } 2 & \text { p model 3 } & \text { p model } 4 & \text { Beta } & \text { IC 95\% Beta } \\ \text { Vitamin D } & & & & & \\ \text { Yes } & 0,788 & 0,794 & 0,813 & - & - & - \\ \text { No } & & & & & \end{array}$

Age
$\begin{aligned} & <70 \text { years } \\ & \geq 70 \text { years }\end{aligned}$

Gender $\quad<0,0001 \quad<0,0001 \quad<0,0001 \quad<0,0001 \quad 14,33 \quad 0,67 ; 11,74$

1-Female

2-Male

\begin{tabular}{lllllll} 
Pain & 0,007 & 0,007 & 0,006 & 0,006 & $-0,51$ & $-0,15 ;-2,77$ \\
\hline & & & & & & \\
$\mathrm{BMI}^{+}$ & 0,899 & - & - & - & - & -
\end{tabular}

\section{Supplement}

$\begin{array}{lllllll}\text { Yes } & 0,057 & 0,056 & 0,055 & 0,048 & -2,33 & -0,11 ;-1,99 \\ \text { No } & & & & & & \end{array}$

Vitamin D status

Sufficiency $\quad 0,834 \quad 0,841$

Hypovitaminosis D

$\begin{array}{llllll}\text { R2 adjusted } & 0,574 & 0,577 & 0,580 & 0,582 & -\end{array}$

${ }^{\dagger}$ Body mass index 


\section{Table 4}

Results of the logFIQ multivariate linear regression analysis.

$\begin{array}{llllll}\text { Variable } & \text { p model } 1 & p \text { model } 2 & p \text { model } 3 & \text { Beta } & \text { IC95\% Beta } \\ \text { Age } & & & & & \\ <70 \text { years } & 0,006 & 0,005 & 0,005 & -0,07 & -0,12 ;-0,02 \\ \geq 70 \text { years } & & & & & \end{array}$

Gender

1-Female $\quad<0,0001 \quad<0,0001 \quad<0,0001 \quad 0,12 \quad 0,07 ; 0,17$

2-Male

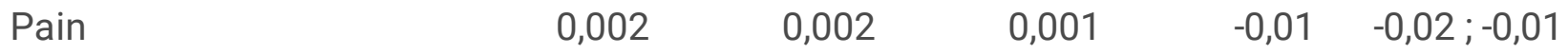

Number of comorbidities

$0,607 \quad 0,596$

Physical activity

Yes

$0,004 \quad 0,004 \quad 0,003 \quad 0,07 \quad 0,02 ; 0,11$

No

Supplement

0,884

R2 adjusted

$0,247 \quad 0,252 \quad 0,255$

